\title{
A Ditadura Militar e o ensino de História: uma relação conflituosa
}

\section{Bruno Rafael Machado Nascimento ${ }^{1}$}

1 Mestrando do Mestrado Profissional em Ensino de História (UNIFAP), Especialista em Metodologia do Ensino de História e Geografia (UNINTER) e Ensino Religioso (FATECH) e Graduado em História (UNIFAP). Bolsista da CAPES, Brasil. E-mail: brunomachado8@outlook.com.

RESUMO: Este artigo tem como objetivo analisar como o ensino da disciplina história foi tratado durante a ditadura militar no Brasil, sobretudo, na década de 1970 . Utilizou-se nesta pesquisa bibliográfica livros e artigos para se chegar a uma síntese sobre como os governos militares buscaram fragmentar o ensino de História através da criação de uma disciplina que uniu História e Geografia no primeiro grau. Dessa forma, percebeu-se que a escola foi compreendida pelos militares como espaço de conformação da sociedade aos seus valores e que o conhecimento histórico foi movido para formar cidadãos patriotas, obedientes e subservientes enfocando a perspectiva tecnicista de preparar tão somente para o mercado de trabalho. Estudar essa temática implica em compreender os caminhos e descaminhos da história da disciplina. É enfrentar um tema ainda sensível em que memórias estão em disputas na sociedade brasileira. Palavras-chave: Educação. Escola. Professores.

The Military Dictatorship and the teaching of History: a conflict

ABSTRACT: This article aims to analyze how the teaching of history was treated during the military dictatorship in Brazil, especially in the 1970s. In this bibliographical research, books and articles were used to arrive at a synthesis on how military governments sought to fragment teaching Of history through the creation of a discipline that united history and geography in the first degree. In this way, it was perceived that the school was understood by the military as a space for conformation of society to its values and that historical knowledge was moved to form patriots, obedient and subservient citizens focusing on the technicalist perspective of preparing only for the labor market. Studying this theme implies understanding the ways and ways of the discipline's history. It is to face a still sensitive subject in which memories are in disputes in the Brazilian society.

Keywords: Education. School. Teachers.

\section{CONSIDERAÇÕES INICIAIS}

Ao longo da história do ensino de História, os Estados sempre tentaram interferir no ensino da disciplina, por exemplo, no fim da Segunda Guerra Mundial foi proibido o ensino de História nos países vencidos (LAVILLE, 1999). A intenção não é entrar no debate proposto por Laville (1999), levantando o questionamento se pela manipulação dos conteúdos ministrados pela História é possível moldar as consciências em prol de determinados objetivos. É fato que os governantes acreditam nisso e por isso a "história é certamente a única disciplina escolar que recebe intervenções diretas dos altos dirigentes e a consideração ativa dos parlamentares. Isso mostra quão importante é ela para o poder" (LAVILLE, 1999, p. 130).

Este artigo traz como problemática compreender como o ensino de História foi tratado durante a ditadura militar brasileira. $\mathrm{O}$ recorte temporal situa-se na década de 
1970 quando o Governo criou a Lei no 5.692 de 1971 que, dentre outras mudanças, incorpora as disciplinas História e Geografia à disciplina Estudos Sociais. Na década de 80 essa realidade perdeu força e em 1986 o Conselho Federal de Educação aprovou a separação definitiva das disciplinas História e Geografia (VIANA, 2014). Para tanto, foram analisadas diversas obras que tratam da problemática proposta num esforço de sintetizar a apresentação da situação do ensino de História no período ditatorial.

A relação passado, presente e futuro é primordial na ciência História e, por isso, pensar "o ensino de História na sua historicidade significa buscar, se não soluções definitivas, ao menos uma compreensão mais clara sobre o que significa, hoje, ensinar História nas escolas" (FONSECA, 2006, p.7). Espera-se que o professor de História, além de dominar os aspectos teórico-metodológicos da disciplina, também saiba a história da disciplina que leciona. A partir da década de 1990 assistiu-se a um debate educacional, mormente sobre os currículos escolares que gerou diversas posições, principalmente na disciplina História. Diante da situação educacional no país, o Governo anunciou mudanças no Ensino Médio que acirraram os ânimos dos professores da educação básica e de pesquisadores, como por exemplo, a Medida Provisória no 746/2016 que instituiu escolas do Ensino Médio em tempo integral e as polêmicas sobre as disciplinas Artes, Educação Física, Filosofia e Sociologia ao tentar facultar essas disciplinas o que gerou reação dos profissionais e educadores.

Existe uma vasta produção, sobretudo no campo da educação sobre a legislação do referido período. No que tange à História, tem-se a professora Selva Guimarães Fon- seca, na obra Caminhos da História ensinada (FONSECA, 2003) que, a partir das análises dos guias escolares e outros documentos, analisa o ensino de História na década de 1970 e 1980 nos Estados de São Paulo e Minas Gerais. Outro trabalho é o artigo intitulado, $O$ Ensino de História no Brasil: trajetória e perspectiva, de Nadai (1993), que faz uma relevante análise histórica da disciplina.

\section{UM PASSEIO PELA HISTÓRIA DO ENSINO DE HISTÓRIA NO BRASIL}

A História enquanto disciplina autônoma surge na França no século XIX no contexto de laicização de toda a sociedade e do fortalecimento das nações modernas (NADAl, 1993). Portanto, a disciplina História estava a serviço do Estado na tentativa de forjar a identidade nacional. No Brasil, o Colégio Pedro II localizado no Rio de Janeiro, fundado em dezembro de 1837 no período regencial, era a referência no ensino, em que em seus currículos, a partir da sexta série, foram introduzidos os estudos históricos (NADAI, 1993). Neste contexto de pósindependência, o Brasil buscou como referência o modelo francês de ensino. Os professores tiveram bastante dificuldade com a falta de material didático adequado, inclusive, sem tradução, como assevera a pesquisadora Nadai (1993, p. 146):

Coerentemente ao modelo proposto, desde o início, a base do ensino centrouse nas traduções dos compêndios franceses - para o ensino de História Universal, o compêndio de Derozoir; para História Antiga, o de Caiz; e para História Romana, o de Derozoir e Dumont. Reformas posteriores cuidaram de adequar o programa 
de estudos do colégio às últimas modificações realizadas nos liceus nacionais da França. Na falta de traduções, apelava-se diretamente para os próprios manuais franceses.

O Brasil também procurava criar sua identidade nacional, pois se vivia num país bastante diversificado etnicamente, social e culturalmente. Como elaborar um projeto para um país com essas características? As elites perceberam que a educação era um bom caminho para construção da identidade. Instituição de destaque neste contexto foi o Instituto Histórico Geográfico Brasileiro (IHGB) fundado em 1838. Ele tinha a missão de "elaborar uma história nacional e de difundi-la por meio da educação, mais precisamente por meio do ensino de História" (FONSECA, 2006, p. 46).

$\mathrm{O}$ instituto acima referido organizou um concurso sobre qual seria a melhor forma de escrever a história do Brasil. O vencedor foi o alemão Von Martius que defendeu a ideia de que se partisse da mistura dos três grupos étnicos (brancos, negros e índios) como formadores da nacionalidade brasileira e, claro, o destaque era dado ao branco "sugerindo um progressivo branqueamento como caminho seguro para a civilização" (FONSECA, 2006, p.46). Não se reconhecia outros grupos sociais como sujeitos históricos, e deste modo, são os indígenas que nas narrativas do instituto ficavam confinados no passado. "Nessa História, os índios apareciam na hora do confronto, como inimigos a serem combatidos ou como heróis que auxiliavam os portugueses" (ALMEIDA, 2010, p.17). Os indígenas do século XIX não eram citados, pois o interesse era representá-los como pessoas que ficaram no passado distante.
E assim a História escolar constitui-se como disciplina no Brasil. Mas que História era essa? Sem dúvida uma História essencialmente política, nacionalista, eurocêntrica que valorizava a monarquia e ação missionária da igreja católica (FONSECA, 2006). Vale ressaltar que muitos membros do IHGB ministravam aulas no Colégio D. Pedro II que, como dito anteriormente, era referência no ensino de História, isto é, servia de modelo para outros colégios na elaboração de programas e orientações de conteúdos a serem ministrados nas escolas públicas.

Interessante que nesse período histórico, ou seja, século XIX, os métodos de ensino eram voltados para a memorização. "Aprender História significava saber de cor nomes e fatos com suas datas, repetindo exatamente o que estava escrito no livro ou copiado nos cadernos" (BITTENCOURT, 2009, p. 67). O sistema de avaliação era aterrorizante, isto é, caso os alunos errassem ou esquecessem alguma palavra ou fato receberiam como punição a famosa palmatória. Infelizmente esta ideia que aprender é sinônimo de memorizar ainda faz-se presente no ensino de História.

Com o advento da República em 1889, o ensino de História voltou-se para a exaltação dos heróis nacionais, ou seja, valorizouse a construção dos mitos, por exemplo, Tiradentes. O ensino da disciplina foi usado para legitimar poderes e valores que exaltavam a ordem estabelecida, ou seja, uma História moralista e patriótica. Com a ascensão de Getúlio Vargas ao poder a partir de 1930 o Estado ficou mais centralizado, ou seja, o poder político ficou nas mãos do Governo Federal. "Alegando a necessidade de substituir as antiquadas instituições políticas brasileiras, Getúlio Vargas prometia a modernização do país mediante a reformu- 
lação do seu modelo econômico e jurídicopolítico" (ABUD, 1993, p.163).

Para Abud (1993), o ensino de História adquiriu um sentido utilitário, pois era visto como instrumento de educação política e de familiarização com os problemas que o desenvolvimento impunha ao Brasil. Neste sentido este ensino casou-se com a ideologia getulista, isto é, a necessidade de modernização e superação dos arcaísmos da sociedade nacional. Um aspecto fundamental deste período foi a valorização dos heróis nacionais com o objetivo de forjar uma identidade de unidade nacional mascarando as desigualdades étnicas, sociais e econômicas. Neste contexto de busca da unidade nacional sobrava pouco espaço para a História regional ou para personagens que não representassem a unidade nacional (ABUD, 1993). Portanto, o ensino foi instrumento de centralização política.

Neste passeio pela história do ensino de História no Brasil, chamou atenção a reflexão realizada por Nadai (1993). Segundo ela, nas décadas de 1950 e 1960 até o início da ditadura, houve um desenvolvimento qualitativo no ensino de História. Atribui-se este avanço à criação dos primeiros cursos em nível universitário para preparar professores para o ensino secundário em 1934, bem como, a criação das Universidades, o que gerou inovação no ensino, mesmo que timidamente. Assim, muitos professores foram recrutados no seio da licenciatura favorecendo a qualidade do ensino. A marca da disciplina História foi a busca da interdisciplinaridade, "houve uma abertura para outras Ciências Humanas, com o entendimento que era necessário superar o isolamento, enfatizando seu caráter problematizador e interpretativo" (NADAl, 1993, p. 156). Logo, a História passa por transformações. Com a implantação da ditadura em 1964, o que ocorreu com o ensino da História?

\section{O ENSINO DE HISTÓRIA NA DITADURA MILITAR}

O ensino no regime militar brasileiro (1964-1985) é objeto de diversas discussões, notadamente sobre o aspecto da legislação que vigorou neste período. Como é uma experiência recente na história do país, permanecem vivas diversas memórias (em disputas) e traumas, porém se faz necessário analisar historicamente este período para evitar o esquecimento. Não é fácil caracterizar a ditadura militar no Brasil, pois adquiriu várias faces e fases. Segundo o historiador Napolitano (2014), até a criação do Ato Institucional número 5 , em dezembro de 1968, a censura prévia não era rigorosa e o terror sistemático do Estado contra os seus opositores ainda não era intenso e vigoroso como foi a partir de 1969. Cassações, perseguições, mortes, cerceamento da liberdade, censura, mas também resistências foram a tônica desse regime. E a educação dentro desse contexto?

De maneira geral, a educação no regime militar é criticada, principalmente, pelo seu aspecto tecnicista, além disso, no que diz respeito ao ensino, acrescenta o filósofo Ghiraldelli Junior (2015, p. 146-147):

Foi pautado em termos educacionais pela repressão, privatização do ensino, exclusão de boa parcela dos setores mais pobres de ensino elementar de boa qualidade, institucionalização do ensino profissionalizante na rede pública regular sem qualquer arranjo prévio para tal, divulgação de uma pedagogia calcada mais em 
técnicas do que em propósitos com fins abertos e discutíveis, tentativas variadas de desmobilização do magistério através de abundante e confusa legislação educacional.

Os governos militares compreendiam a escola como espaço privilegiado de divulgação de sua ideologia, como assevera Filgueiras (2008, p. 84-85):

A concepção de educação do regime militar estava centrada na formação de capital humano, em atendimento às necessidades do mercado e da produção. A escola era considerada uma das grandes difusoras da nova mentalidade a ser inculcada - da formação de um espírito nacional.

Esta valorização do tecnicismo pedagógico expressava bem o objetivo central da educação neste período, ou seja, fornecer mão de obra qualificada para o mercado de trabalho, pois se fazia necessário inserir o país no cenário político e econômico do capitalismo internacional. Assim, a formação geral, especialmente a da área de humanas, foi afetada. Além disso, as escolas não foram estruturadas para cumprir tal função.

Neste contexto houve uma aproximação ainda maior com os Estados Unidos que viam nos governos militares latinoamericanos elementos garantidores dos interesses da América do Norte para evitar a disseminação das ideias comunistas (SILVEIRA, 2009). Para Silveira (2009), através dos convênios realizados a partir de 1964 entre o Ministério de Educação e Cultura (MEC) e a United States Agency for International Development (USAID), agência de desenvolvimento norte-americana, a instituição americana ofertava apoio técnico e financeiro aos países que aderissem aos princípios educacionais e políticos por ela engendrados. Após o golpe de 1964, este apoio norte-americano ampliou-se. Vários especialistas norte-americanos vieram ao Brasil e técnicos do MEC foram aos Estados Unidos para serem treinados. $\mathrm{O}$ discurso que fundamentava os acordos foi o da modernização da educação na perspectiva capitalista. Desta forma:

Os muitos acordos firmados entre o MEC e a USAID no Brasil, assinados dentro desse espírito de ajuda, inseridos numa política de boa vizinhança, trouxeram como resultado concreto para educação uma transformação radical, qual seja, a unificação do ensino primário ao ginásio e a profissionalização do colégio (SILVEIRA, 2009, p.64-65).

Na ditadura foi negado à História o estatuto de disciplina autônoma; aliás, ela desapareceu do currículo no primeiro grau, com a introdução dos Estudos Sociais. E só no segundo grau, numa única série, a História era obrigatória. Mas, por que com a História? O que ocorria nas universidades?

A despeito de toda tentativa de controle, perseguições e limitações, a produção historiográfica renovou-se sob a influência do materialismo histórico que trouxe além de métodos de análise, novas temáticas, por exemplo, escravidão, economia colonial, classe trabalhadora, camponeses e mulheres (NADAl, 1993). Inserida no contexto ditatorial, essa produção histórica não chegou ao grande público e ficou reservada às universidades.

Para Nadai (1993), a ideologia implantada à disciplina História tinha uma função determinada, isto é, formar indivíduos obedientes, subservientes e ordeiros. Cidadãos 
que fossem patriotas e que reproduzissem a moral estabelecida pela ideologia dos militares. Contudo, as discussões pelo Estado brasileiro sobre a educação, com o objetivo de uma educação moral e cívica dos cidadãos é anterior à ditadura de 1964. A ideia de proporcionar uma educação cívica e patriótica remonta os debates do início da República chegando, inclusive, em alguns momentos ser ministrada como disciplina própria e, em outros, como orientação para as escolas que perpassava todas as disciplinas numa forma de transversalidade (FILGUEIRAS, 2008).

A ideia era formar o cidadão no espírito de passividade e obediência em relação àqueles cuja função social seria fazer política, portanto, os que resolveriam os problemas do Brasil. Forjou-se a ideia de que o Brasil caminharia para um futuro promissor, mas que seria necessária a união de todos para a concretização desta meta, inclusive, o conhecimento histórico foi mobilizado para formar os cidadãos de acordo com os princípios do regime militar.

Com a Lei no 5.692 de 1971, ocorreram várias mudanças no âmbito educacional, por exemplo, o ensino de $1 \underline{a}$ a 8 o série passou-se a chamar de 1 o grau. Já o ensino de 2o grau voltou-se para a formação profissional dos alunos (FONSECA, 2003). Essas transformações expressavam as ideias já referidas que norteavam as ações dos governos militares, isto é, o ideário de segurança nacional, o aspecto tecnicista do ensino e a formação cívica. Foi também por meio dessa lei que a disciplina História juntamente com a Geografia perdeu sua autonomia e passou a integrar a disciplina de Estudos Sociais que englobava os conteúdos das duas disciplinas. Segundo Fonseca (2003), até 1977 a disciplina Estudos Sociais foi implantada no 10 grau. A partir desse ano, os guias curriculares dos Estados de São Paulo e Minas Gerais, por exemplo, reintroduziram História e Geografia com a permanência dos Estudos Sociais. Somente em 1986, por meio do parecer 785/ 1986 do Conselho Federal de Educação, a História e Geografia readquiriram suas respectivas autonomias (VIANA, 2014).

Este ordenamento jurídico que acabou com a autonomia da História e Geografia surgiu no contexto de forte repressão, mas também de crescimento econômico. Ainda no final de 1968, o Presidente Costa e Silva, assinou o Ato Institucional número 5 ( $\mathrm{Al}$ 5). O qual concentrava ainda mais o poder nas mãos do presidente. Vieira (1994, p. 27) elenca os poderes:

a) fechar o Congresso Nacional, assembléias estaduais e câmaras municipais; b) cassar mandatos de parlamentares; c) suspender por dez anos os direitos políticos de qualquer pessoa; d) demitir, remover, aposentar ou pôr em disponibilidade funcionários federais, estaduais e municipais; e) demitir ou remover juízes; f) suspensão das garantias do Poder judiciário; g) decretar estado de sítio sem qualquer impedimento; h) confiscar bens como punição por corrupção; i) suspensão de habeas - corpus em crimes contra a segurança nacional; j) julgamento de crimes políticos por tribunais militares; k) legislar por decreto e expedir outros atos institucionais ou complementares; I) proibição de exame, pelo Poder judiciário, de recursos impetrados por pessoas acusadas por meio do Ato Institucional n.o 5 .

Este Ato deixou marcas no Brasil, por exemplo, prisões sem o devido processo legal, perseguições e torturas. Os poderes 
legislativo e judiciário foram ainda mais fragilizados. O Al-5 vigorou durante os governos de Médici e do Geisel. Médici assumiu a presidência em outubro de 1969 e utilizou fartamente os poderes constituídos após o referido Ato para aumentar a repressão aos grupos que lutavam contra o regime. Foi sob a vigência dele que foi criada a Lei $n$ 5.692 de 1971, que referimos acima e que trata sobre as mudanças que afetaram a História e toda organização educacional. Período de grande censura em que "jornais e revistas tinham de registrar-se na Polícia Federal, além de obedecer a uma série de exigências" (VIEIRA, 1994, p. 36).

lêda Viana (2014) chama atenção para um aspecto interessante da Lei no 5.692 de 1971. Como a sociedade reagiu às transformações? A despeito do contexto de repressão e autoritarismo, o clima foi de euforia devido o crescimento econômico, conhecido como milagre econômico e seus impactos nos campos de emprego, urbanização e cultura do país o que gerou omissão, adesão e até apoio de uma parte significativa da população às diretrizes desenvolvimentistas do Governo (VIANA, 2014). As camadas médias urbanas foram beneficiadas com a facilidade de crédito, o incentivo ao consumo com o abarrotamento de novidades como automóveis, televisores e câmeras. "Para completar a felicidade do brasileiro, ainda existia a possibilidade de o assalariado finalmente ' dar o salto da casa própria' e comprar o imóvel financiado pelo recém-criado Banco Nacional de Habitação (BNH)" (SCHWARCZ; STARLING, 2015, p. 453). O controle exercido pela ditadura na sociedade, especialmente no governo de Médici, foi sustentado pelo crescimento econômico e pela gigantesca estrutura de propaganda.
Foi nesse contexto que a diluição das disciplinas História e Geografia ocorreram. Situação difícil para os professores dessas duas disciplinas que tiveram suas identidades profissionais fragilizadas. Neste período surgiram as licenciaturas curtas e longas em Estudos Sociais. "A duração das licenciaturas curta e longa deve ser respectivamente de 1200 horas, o que equivale a um ano e meio letivo, e 2200 horas, o equivalente a 3 anos letivos" (FONSECA, 2003, p.27). Fonseca $(2003$, p. 63) destaca ainda:

O governo, como demonstrou o quadro anterior, detém a função planejadora e os professores vão paulatinamente sendo desapropriados de sua função criadora. 0 processo de desqualificação do professor, estrategicamente colocado pelo Estado, retira daquele profissional a função de pensar. Para que ensinar; a quem ensinar; como ensinar e quando ensinar: autoritariamente, estas questões passam a ser respondidas pelos especialistas, alheios ao processo de ensino/aprendizagem.

Para agravar a situação e a promoção da desqualificação do professor de História, o Ministério da Educação, no ano de 1976, editou uma portaria que permitia somente aos licenciados em Estudos Sociais ministrarem aulas da citada disciplina. Os formados em História e Geografia foram praticamente excluídos do ensino de 10 grau, pois passaram a ministrar as poucas aulas que restavam no 2 o grau (FONSECA, 2003). Segundo Fonseca (2003), o profissional formado na licenciatura curta estava tendencioso a "atender aos objetivos do Estado, aos ideais de Segurança Nacional do que um outro profissional oriundo de um curso de licenciatura plena em História, apesar das limitações deste" (FONSECA, 2003, p.28). Isso in- 
fluenciou no cotidiano escolar, pois professores malformados não conseguiam dar conta de um ensino de qualidade. Profissionais que não dominam os fundamentos mínimos da História não conseguem incentivar o pensar historicamente e o pensamento autônomo dos alunos.

Os conteúdos referentes a História, na disciplina Estudos Sociais, refletiam uma perspectiva substancialmente política da História. Ao dissertar sobre essa disciplina, Martins (2014) afirma que a memorização de datas e fatos marcantes era valorizada. Utilizava-se o conhecimento histórico para exaltar grandes personagens como exemplos a serem seguidos, bem como, certos grupos sociais e étnicos foram deixados de lado. Ao analisar os conteúdos de Estudos Sociais, Fonseca (2003) afirma que eram conteúdos generalizantes e sem a especificidade do conhecimento histórico. Também Fonseca (2003) destaca que o processo de ensino e aprendizagem reforçava apenas a dimensão reprodutora. Realidade não muito diferente do que se vinha trabalhando no ensino de História mesmo antes da ditadura militar. Ressalta-se que a crítica que se faz a este método é contra a memorização mecânica que não traz sentido e significado algum para os alunos, ou seja, a mera repetição e não contra o desenvolvimento intelectual de memorizar.

Em síntese, o objetivo era dissolver o conhecimento histórico escolar para evitar a formação da juventude. A História esteve, como dito anteriormente, a serviço do Estado para justificar seu projeto. Fonseca (2003) afirma que a Lei no 5.692 de 1971 descaracterizou o ensino de História no 10 grau. Na ditadura, a escola perdeu autonomia, pois cabia aos professores reproduzirem as diretrizes emanadas dos órgãos su- periores. Além disso, outras disciplinas foram criadas e trabalhavam conteúdos que eram ministrados na disciplina História, como Educação Moral e Cívica (EMC) e o reforço na disciplina Organização Social e Política Brasileira (OSPB) que foi criada ainda em 1962. Elas tinham o objetivo de incutir valores e conceitos propagados pelo regime (ALMEIDA NETO, 2014).

A EMC foi criada por meio do Decreto-Lei no 869/69. Possuía o objetivo de "construir um ideário patriótico, com uma nação forte, que ressaltava os valores da moral, da família, da religião/fé e da defesa da Pátria e inculcava valores anticomunistas nos jovens e crianças" (FILGUEIRAS, 2008, p.84). Nessa perspectiva de unidade da nação, as diferenças e desigualdades seriam ocultadas em nome da exaltação da pátria que era maior que todos. Corrobora-se com a pesquisadora Fonseca (2003) quando assevera que não se tratava apenas de uma disciplina, mas uma doutrina difundida pelo Estado ditatorial.

A disciplina OSPB tinha por função principal apresentar as estruturas administrativas e os princípios institucionais do Estado. "A disciplina de OSPB deveria compor a parte complementar do currículo, presente apenas em algumas das séries do 10 e 20 graus, e surgir como equivalente a um estudo da realidade social e política brasileiras" (MARTINS, 2014, p.44). Martins (2014) afirma que essa disciplina na ditadura militar atuava como legitimadora das estruturas e das ações do Estado. Além disso:

Em sua característica meramente escolar, e sem uma disciplina acadêmica que fornecesse suporte para configuração dos conhecimentos, a OSPB agia, juntamente com a EMC, com uma característica muito

https://periodicos.unifap.br/index.php/estacao Macapá, v. 6, n. 3, p. 29-39, set./dez. 2016 
mais prescritiva que os demais conteúdos escolares, uma vez que seus princípios eram especialmente os de promover o entendimento da ordem social e do organograma estatal. Dentre os seus conteúdos, destacam-se as definições dos três Poderes brasileiros - o Executivo, o Legislativo e o Judiciário, a organização administrativa do Estado, o conceito de participação, de comunidade, de sociedade. E, embora, por vezes, seu conteúdo se confundisse com o de EMC, ela pode ser considerada uma disciplina muito mais racional e técnica, bastante pertinente para o modelo curricular que se estabeleceu durante a ditadura, que abraça o tecnicismo como matriz curricular e pedagógica (MARTINS, 2014, p.45).

Observa-se o quanto a educação foi instrumentalizada para atingir determinados fins durante o período ditatorial, mas apesar da implantação e difusão das ideias moralizadoras e disciplinadoras no sistema educacional brasileiro, existiram resistências, pois o "controle e a dominação não se fazem de forma absoluta" (FONSECA, 2003, p.40). Muitos professores de História tiveram que ministrar aulas de EMC e OSPB, pois as escolas diminuíram a carga horária de História. Eles criaram várias estratégias para não reproduzirem a ideologia da ditadura. Almeida Neto (2014) realizou uma pesquisa interessante sobre o cotidiano escolar, para tanto usou como fontes: relatórios de estágios das práticas de ensino de História, atas de reuniões, livros de ocorrências disciplinares, livros de termos de visitas de supervisão etc., de algumas escolas de São Paulo. Através dessas fontes, ele buscou captar a prática na sala de aula. Percebeu que os professores criaram formas de não seguir as diretrizes estatais, fugindo de todo o controle e perseguição. Alguns professores buscavam novos métodos e temas, outros usavam outros livros, jornais e revistas em busca de uma nova forma de ensino e aprendizagem (ALMEIDA NETO, 2014).

\section{CONSIDERAÇÕES FINAIS}

Da leitura bibliográfica analisada percebeu-se o quanto o ensino de História no regime militar foi descaracterizado. Os governos ditatoriais tentaram de todas as formas controlar a formação da juventude. A escola foi entendida como lugar apropriado para difundir a ideologia defendida pelo Estado, com a lei implementada em 1971 que uniu História e Geografia em uma única disciplina, Estudos Sociais. O conhecimento histórico escolar ficou debilitado, pois o despreparo dos professores, formados em licenciaturas curtas, prejudicou o ensino e aprendizagem nas escolas. Soma-se a isso, a ênfase nas disciplinas OSPB e EMC que atendiam perfeitamente os interesses dos militares.

Contudo, existiram várias formas de resistências. Um aspecto é a legislação, ou seja, aquilo que se pretende, e outro é a prática na sala de aula. Não existe uma transferência pura entre aquilo que se planeja e aquilo que se executa. Existem poucos estudos sobre a prática escolar na sala de aula no período ditatorial, de fato, encontrou-se na bibliografia analisada apenas um estudo. A dificuldade são as fontes, pois no país existe pouca preocupação com a guarda de documentos em arquivos. A medida que as pesquisas que entendem a escola como lugar autônomo, ou seja, com seus próprios valores, rituais, práticas, normas, modelos, objetivos e tradições avan- 
cem, serão revelados, além do controle promovidos pelos agentes do Estado, as diversas resistências no interior das instituições educacionais.

Pesquisar sobre a história do ensino de História é mergulhar num oceano de experiências positivas e negativas. É olhar para o passado e compreender que a despeito de avanços e mudanças, ainda existem permanências que precisam ser superadas para que o professor jamais perca de vista seu potencial criativo que pode ajudar os alunos, que frequentam as aulas de História, a reconhecerem-se como agentes históricos, portanto, senhores das suas escolhas.

\section{REFERÊNCIAS}

ABUD, K. M. O ensino de história como fator de coesão nacional: os programas de 1931. Revista Brasileira de História, São Paulo, v.13, n. 25/26, p. 163-174, 1993.

ALMEIDA, M. R. C. de. Os índios na história do Brasil. Rio de Janeiro: Editora FGV, 2010. (Coleção FGV de bolso).

ALMEIDA NETO, A. S. de. Cultura escolar e ensino de história em tempos de ditadura militar brasileira. OPSIS, Catalão-GO, v. 14, n. 2, p.56-76, jul./dez. 2014.

BITTENCOURT, C. M. F. Ensino de história: fundamentos e métodos. 3. ed. São Paulo: Cortez, 2009. (Coleção docência em formação).

FILGUEIRAS, J. M. A produção didática de educação moral e cívica: 1970-1993. Cadernos de Pesquisa: Pensamento educacional, Curitiba, v. 3, p. 81-97, 2008.

FONSECA, S. G. Caminhos da história ensinada. 7. ed. Campinas, SP: Papirus, 2003. (Coleção Magistério: Formação e trabalho pedagógico).

FONSECA, T. N. de L. e. História \& ensino de
História. 2. ed. Belo Horizonte: Autêntica, 2006.

GHIRALDELLI JUNIOR, P. História da educação brasileira. 5. ed. São Paulo: Cortez, 2015.

LAVILLE, C. A guerra das narrativas: debates e ilusões em torno do ensino de História. Revista Brasileira de História, São Paulo, v.19, n.38, p. 125-138, 1999.

MARTINS, M. do C. Reflexos reformistas: o ensino das humanidades na ditadura militar brasileira e as formas duvidosas de esquecer. Educar em Revista, Curitiba, n. 51, p. 37-50, jan./mar. 2014.

NADAI, E. O Ensino de História no Brasil: trajetória e perspectiva. Revista Brasileira de História, São Paulo, v.13, n. 25/26, p. 143-162, 1993.

NAPOLITANO, M. 1964: História do regime militar brasileiro. São Paulo: Contexto, 2014.

SCHWARCZ, L. M.; STARLING, H. M. Brasil: uma biografia. São Paulo: Companhia das Letras, 2015.

SILVEIRA, M. da. Escolas, ensino de história e identidades em tempos de ditadura militar. 2009. 157 f. Tese (Doutorado em História) - Universidade Federal do Rio Grande do Sul. Porto Alegre, 2009.

VIANA, I. O ensino de história na ditadura civil-militar com a institucionalização dos estudos sociais. PLURAL, Revista do Programa de Pós-Graduação em Sociologia da USP, São Paulo, v.21.1, p. 9-30, 2014.

VIEIRA, E. A república brasileira: 19641984. São Paulo: Moderna, 1994.

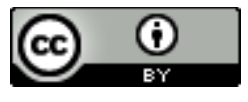
access article distributed under the terms of the Creative Commons Attribution License, which permits unrestricted use, distribution, and reproduction in any medium, provided the original work is properly cited. 
Artigo recebido em 08 de dezembro de 2016.

Avaliado em 26 de janeiro de 2017.

Aceito em 31 de janeiro de 2017.

Publicado em 28 de março de 2017.

Como citar este artigo (ABNT):

NASCIMENTO, Bruno Rafael Machado. A

Ditadura Militar e o ensino de História: uma relação conflituosa. Estação Científica (UNIFAP), Macapá, v. 6, n. 3, p. 29-39, set./dez. 2016. 